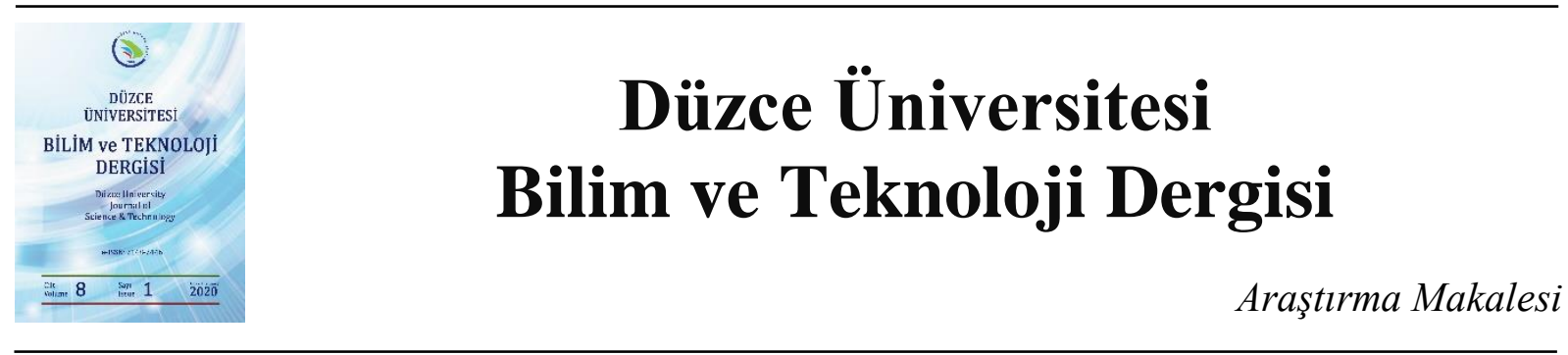

\section{Robotik MAG Kaynak Metodunda XAR 500 Serisi Çeliklerin Mikrosertliğine Farklı Kaynak Akımlarının ve Hızlarının Etkisi}

\author{
Volkan ONAR ${ }^{\mathrm{a}, *}$ \\ ${ }^{a}$ Makine ve Imalat Mühendisliği Bölümü, Teknoloji Fakültesi, Pamukkale Üniversitesi, Denizli, TÜRKIYYE \\ *vonar@pau.edu.tr \\ DOI: $10.29130 /$ dubited.646727
}

\begin{abstract}
ÖZET
Bu çalışmada, XAR (eXtra Aşınma Dayanımı) çeliklerinin robotik MAG kaynağında kaynak akımının kaynaklı birleştirmelerin mikrosertliği üzerine etkisi incelenmiştir. Bu çalışmada, ağır hizmet makinelerinde kullanılan 4 mm kalınlıktaki XAR 500 çeliğinin MAG kaynak yöntemiyle birleştirilmesinde kaynak akımı yoğunluğunun mikrosertliğe etkisi incelenmiştir. Kaynaklanmış numunelerin hazırlanmasında hız, gerilim ve akım kontrollü MAG kynak robotu kullanılmıştır. 140A, 160A ve 180A olmak üzere üç farklı kaynak akım yoğunluğu seçilmiştir. Kaynak hızı 350mm/dak olarak sabit tutulmuştur. Kaynak hızının etkisini test etmek için 300mm/dak, 350mm/dak, $400 \mathrm{~mm} /$ dak ve $450 \mathrm{~mm} /$ dak. olarak seçilmiş kaynak akım şiddeti 160A' de sabit tutulmuştur. $1 \mathrm{~mm}$ kalınlığında MG-2 kaynak teli kullanılmıştır. \%86 Ar, \%12 $\mathrm{CO}_{2}$ ve \%2 $\mathrm{O}_{2}$ içeren karışım gaz kullanılmıştır. Sonuç olarak, bu malzeme gruplarının kaynaklı bağlantılarında ısı tesiri altındaki bölge (ITAB) sertliğinin azaldığı gözlenmiştir. Bu nedenle ITAB sertliğinin azalması durumunda çatlak riskinin azaldığı gözlenmiştir. Elde edilen kaynaklı bağlantılarda optimum sertlik oranını sağlayan kaynak akımı ve kaynak hızı kullanıcılara sunulmuştur.
\end{abstract}

Anahtar Kelimeler: XAR Çelikleri, Robotik MAG Kaynă̆ı, Mikrosertlik

\section{Effect of Different Welding Currents and Speeds on Microhardness of XAR 500 Series Steels in Robotic MAG Welding Method}

\begin{abstract}
$\underline{\text { ABSTRACT }}$
In this study is to investigate the effect of welding current on microhardness in combining XAR (eXtra Wear Resistance) steels with robotic MAG welding method. In this study, the effect of welding current intensity on microhardness in combining XAR 500 steel of 4 mm thickness used in heavy duty machine with MAG welding method was investigated. In the preparation of welded samples, MAG welding robot with speed, voltage and current control is used. Three different welding current densities were selected as welding current intensity 140A, $160 \mathrm{~A}$ and $180 \mathrm{~A}$. Welding speed was kept constant at $350 \mathrm{~mm} / \mathrm{min}$. In order to test the effect of the welding speed, the welding current was kept constant at $160 \mathrm{~A}$ and at speeds of $300 \mathrm{~mm} / \mathrm{min}, 400 \mathrm{~mm} / \mathrm{min}$ and $450 \mathrm{~mm} / \mathrm{min}$. MG2 welding wire with $1 \mathrm{~mm}$ thickness was used. Mixed gas with $86 \% \mathrm{Ar}, 12 \% \mathrm{CO}_{2}$ and $2 \% \mathrm{O}_{2}$ was used. Microhardness obtained from welded joints were analyzed. As a results, it has been observed decrease of HAZ hardness on welded joints of this material groups. Therefore, was observed decrease of crack risk in HAZ of weldment when decreased HAZ hardness. The welding current which providing the optimum hardness ratio in the obtained welded joints was presented to the users.
\end{abstract}

Keywords: XAR Steels, Robotic MAG welding, Microhardness 


\section{GİRIS}

Gelişen teknoloji ve kullanım isteklerine bağlı olarak çelik üreticileri her geçen gün kullanıcıların isteklerine göre yeni çelikler üretmektedirler. Ürettikleri bu çeliklerin bazıları aşınma ve yüksek tokluk özelliklerine sahipken bazıları da yüksek şekillendirilebilme kabiliyetine, yüksek akma/çekme dayanımlarına ve yüksek korozyon dayanımları gibi kullanıcı tarafından istenilen mekanik ve kimyasal özellikleri karşılamak amacındadırlar. Bu nedenle AHSS (Ekstra Yüksek Dayanımı Çelikler) ve UHSS (Ultra Yüksek Dayanımlı Çelikler) çelikleri günümüzde inşaat, otomotiv, çekici, taşımacılık, su üstü uygulamaları ve maden arama endüstrisi gibi alanlarda araç, ekipman ve bina inşa sektörünün vazgeçilmez bileşenleri olmuşlardır. Bununla birlikte çelik üreticileri her geçen gün bu çelik gruplarını geliştirici çalışmalar yapmaktadırlar.

Son yıllarda ağır iş makinalarının hemen hemen hepsinde AHSS ve UHSS çelikleri imalat çeliklerine göre farklı özellikler taşıdıklarından tercih sebebi olmuşlardır. Bu çelik grupları içerisinde en yaygın olarak kullanılan çelikler XAR (eXtra Aşınma Dayanımı) çelikleridir. Yüksek mukavemet, hafiflik, yüksek aşınma ve korozyon direncine sahip olmaları günden güne kullanım alanlarının artmasını sağlamaktadır. Bu çeliklerin üretimi haddeleme yöntemi ile yapılmakta ve haddeleme işlemi sonrası mikroyapısında martenzit yapısının oluşması için su verme veya su verme + temperleme ssıl işlemlerine tabi tutulmalarıdır. Bu işlemlerden sonra çeliğin sertliği artmakta ve buna paralel olarak da aşınma dayanımları da artmaktadır. Kullanım alanları incelendiğinde asfalt makinaları, ağır iş makinalarının çene ve yük taşıma kasalarının imalatında ekstra aşınma direncine sahip olması, diğer imalat çeliklerine göre 5 kat daha dayanıklı olmaları sebebiyle yaygın olarak kullanıldığı gözlemlenmektedir [1-10]. Kimyasal bileşimlerindeki alaşım elementlerinin miktarlarının az olmasından dolayı $\mathrm{C}_{\text {eş }}$ (Karbon Eşdeğerliliği) oranı düşüktür. Bu oranın düşük olmasından dolayı da kaynak kabiliyetleri iyidir. Sahip oldukları ekstra özelliklerinden dolayı XAR çeliklerinin emniyetli bir biçimde birleştirilmesi önem arz etmektedir. Bilindiği üzere çeliklerin birleştirilmesinde kullanılan en yaygın yöntem kaynak yöntemidir. Ancak, emniyetli bir birleştirme için kaynak yöntemi ve uygulanan kaynak parametreleri çok önemlidir. Bu yüzden makina imalatında, taşımacılık sektöründe ve maden endüstrisinde ekonomik ve pratik bir yöntem olması, kesintisiz kaynak yapılabilmesi, parametrelerin kontrolünün sağlanabilmesi ve otomasyona uygunluğu nedeni ile gazaltı ark kaynak (MIG-MAG) yöntemi en çok tercih edilen birleştirme yöntemi olarak kullanılmaktadır [11-16]. Bununla birlikte Gür ve arkadaşları [17] plazma kaynak yöntemi ile Hardox 400 ve AISI 304 çeliklerini Argon gaz atmosferinde ilave tel kullanmadan termal genleşme katsayıları farklı olan bu iki malzemeyi başarılı bir şekilde birleştirmişlerdir. Correa ve arkadaşları [18] farklı kalınlıktaki Hardox 450 plakaları farklı kaynak ağızlarında başarılı bir şekilde MAG kaynak yöntemi ile düşük 1sı girdisine sahip düşük kaynak akım şiddetlerinde elde edilen birleştirmelerin bükme testinde daha dayanımlı olduklarını tespit etmişlerdir. Birleştirmeler öncesinde hiçbir ön işlem ve son işlem yapılmaksızın (ön tav ve son tav) başarılı kaynaklı birleştirmeler yapılabileceğini söylemişlerdir. İnce kesite sahip olan kaynaklı birleştirmelerde 1sı girdisinden kaynaklı daha başarılı birleştirmelerin elde edildiğinin tespit etmişleridir. Sezgin ve arkadaşları [19] Hardox 450 çeliğini farklı kaynak akımları seçerek tozaltı ark kaynak yöntemi ile kaynaklanabilirliğini incelemişler ve penatrasyonun yüksek akımlarda daha iyi olduğunu ancak yüzeyin iyi temizlenmemesinden dolay1 yüzeyde gözeneklerin olduğunu tespit etmişlerdir. Frydman ve arkadaşları [20] Hardox 600 çeliklerini çift taraflı V kaynak ağzı açarak TIG kaynak yöntemi ile birleştirmişler ve kaynaklı birleştirmelerde, kaynak parametrelerinin mikroyapı ve mekanik özelliklerine olan etkilerini incelemişlerdir. Çalışma sonucunda kaynaklı birleştirilen malzemelerin kaynak bölgelerindeki sertliğin ana metal sertliğinden daha düşük olduğunu belirlemişleridir. Yine Konat ve arkadaşları [1] tozaltı kaynak yöntemi le Hardox 400 ve Hardox 500 çeliklerini kendi arlarında birleştirmişlerdir. Kaynak bölgesindeki sertliğin ana malzemelerin sertliğinden daha düşük olduğunu tespit etmişler ve farklı 1sıl işlemler uygulayarak bu düşüşü minimize etmişlerdir. Bramowizc ve arkadaşları [21] XAR 400 çeliğini V kaynak ağzı açarak başarılı bir şekilde birleştirmişlerdir. Yapılan birleştirmelerin mikroyapısal ve mekanik özelliklerindeki değişiklikleri incelemişlerdir. Sonuç olarak, ısının etkisiyle kaynaklı birleştirmelerde karmaşık mikroyapıların olduğunu ve yine ısının etkisiyle kaynaklı bölgede ana metalden daha az sertlik değerlerinin olduğunu tespit etmişlerdir. 
Bu çalışmada, farklı kaynak akım şiddetlerinin ve farklı kaynak hızlarının XAR 500 serisi çeliklerin robotik MAG kaynak yöntemi ile birleştirilmesinde kaynak akım şiddetlerinin ve kaynak hızlarının kaynaklı bölgenin sertliğine olan etkisi incelenmiştir.

\section{MATERYAL VE METOT}

$\mathrm{Bu}$ çalışmada aşınmaya karşı dayanıklı 150x120x4 mm ölçülerine sahip XAR 500 çelik levhalar kesilmiş daha sonra da kaynak öncesi yüzeyleri temizlenmiştir. Robotik MAG kaynak yöntemi ile alın alına birleştirilmiştir. Çelik levhaların boyutları şematik olarak Şekil 1'de verilmiştir.

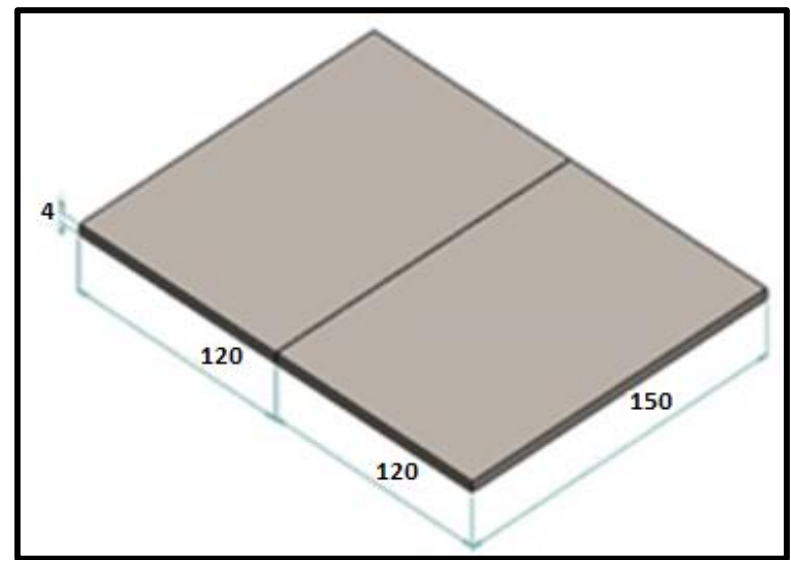

Şekil 1. Birleştirilen levhaların şematik olarak ölçüleri

Birleştirme sırasında Panasonic marka kaynak robotu kullanılmış her parametrenin istikrarlı olması sağlanmıştır. Kullanılan kaynak robotu Şekil 2'de verilmiş̧ir. Birleştirilen levhalardan daha sonra sertlik analizi için numuneler alınmıştır. Kullanılan XAR 500 çelik levhaların mekanik ve kimyasal özellikleri Tablo 1 ve Tablo 2'de sırasıyla verilmiştir.

Tablo 1. XAR 500 çelik plakanın mekanik özellikleri

\begin{tabular}{ccccc}
\hline $\begin{array}{c}\mathbf{C E T} \\
\mathbf{\%}\end{array}$ & $\begin{array}{c}\mathbf{R}_{\mathbf{e}} \\
\left(\mathrm{N} / \mathrm{mm}^{2}\right)\end{array}$ & $\begin{array}{c}\mathbf{R}_{\mathbf{m}} \\
\left(N / \mathrm{mm}^{2}\right)\end{array}$ & $\begin{array}{c}\text { Uzama } \\
(\%)\end{array}$ & $\begin{array}{c}\text { Sertlik } \\
(H R C)\end{array}$ \\
\hline 0,41 & 1300 & 1600 & 9 & 540 \\
\hline
\end{tabular}

Tablo 2. XAR 500 çelik plakanın kimyasal bileşimi

\begin{tabular}{cccccccc}
\hline C \% & Si \% & Mn \% & P \% & Mo \% & B \% & S \% & Cr \% \\
\hline$<0,28$ & $<0,80$ & $<1,50$ & $<0,025$ & $<0,50$ & $<0,005$ & $<0,010$ & $<1,00$ \\
\hline
\end{tabular}




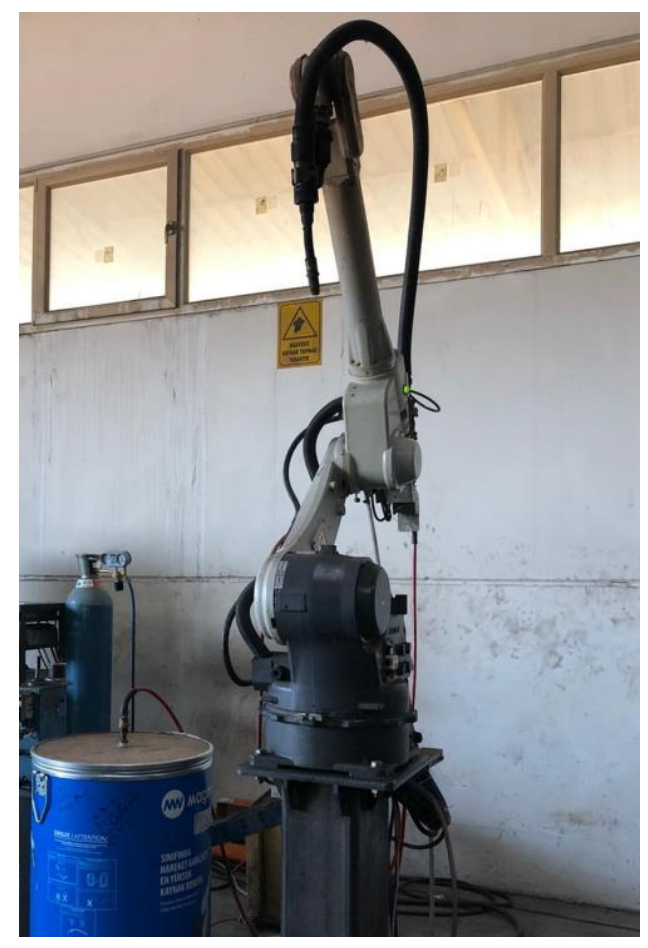

Şekil 2. Panasonic marka kaynak robotu

Kaynak sırasında ilave metal olarak MG-2 kaynak teli ve karışım gaz kullanılmıştır. Kullanılan ilave telin kimyasal bileşimi ve koruyucu gazın içeriği sırasıyla Tablo 3 ve Tablo 4'de sırasıyla verilmiştir.

Tablo 3. MG-2 kaynak telinin kimyasal bileşimi

\begin{tabular}{cccc}
\hline Kaynak Teli & C \% & Si \% & Mn \% \\
\hline MG-2 & 0,08 & 0,85 & 1,50 \\
\hline
\end{tabular}

Tablo 4. Koruyucu gazın kimyasal bileşimi

\begin{tabular}{cccc}
\hline Koruyucu Gaz & Ar \% & $\mathbf{C O}_{\mathbf{2}} \%$ & $\mathbf{O}_{\mathbf{2}} \%$ \\
\hline HB 212 & 86 & 12 & 2 \\
\hline
\end{tabular}

Kaynak sırasında kullanılan parametre ve değişkenler şu şekilde seçilmiştir: Bilindiği üzere kaynaklı birleştirmenin mikroyapı ve mekanik özelliklerini etkileyen en önemli faktör 1sı girdisidir. Isı girdisini ise kaynak amperi ve kaynak hızı parametreleri etkilemektedir. Is1 girdisi hesaplanırken kullanılan bağıntı Eş. 1'de verilmiştir. Isı girdisinin etkisini incelemek amacıyla 3 farklı kaynak akımı ve 4 farklı kaynak hızı deneyler esnasında kullanılmıştır. Kaynak parametreleri Tablo 5' de verilmiştir.

$$
H=\mathrm{\eta} \frac{\mathrm{I} * \mathrm{~V} * 60}{S * 1000}
$$
H: Is1 Girdisi (kJ/mm)
П: Verimlilik
I: Kaynak Akım Şiddeti (A)
E: Kaynak Voltaj1 (V)
S: Kaynak Hızı (mm/dak) 
Elde edilen kaynaklı numuneler Şekil 3'de verilmiştir. Daha sonra hassas kesme cihazı ile kesilen kaynaklı numunelere metalografik işlemler uygulanmış ve $\% 5$ 'lik Nital çözeltisiyle yüzeyleri dağlandıktan sonra mikrosertlik değerleri sertlik ölçme cihazında ölçülmüştür.

Tablo 5. Kaynak parametreleri

\begin{tabular}{ccccccc}
\hline Numune & $\begin{array}{c}\text { Akım } \\
(A)\end{array}$ & $\begin{array}{c}\text { Voltaj } \\
(V)\end{array}$ & $\begin{array}{c}\text { Kaynak Hızı } \\
(\mathrm{mm} / \mathrm{dak})\end{array}$ & $\mathbf{\eta}$ & $\begin{array}{c}\text { Gaz Debisi } \\
(\mathrm{l} / \mathrm{dak})\end{array}$ & $\begin{array}{c}\text { Isı Girdisi } \\
(\mathrm{kJ} / \mathrm{mm})\end{array}$ \\
\hline 1 & 140 & 17,7 & 350 & 0,8 & 10 & 0,341 \\
\hline 2 & 160 & 19,18 & 350 & 0,8 & 10 & 0,421 \\
\hline 3 & 180 & 22,20 & 350 & 0,8 & 10 & 0,533 \\
\hline 4 & 160 & 16,44 & 300 & 0,8 & 10 & 0,491 \\
\hline 5 & 160 & 19,16 & 400 & 0,8 & 10 & 0,368 \\
\hline 6 & 160 & 19,23 & 450 & 0,8 & 10 & 0,327 \\
\hline
\end{tabular}

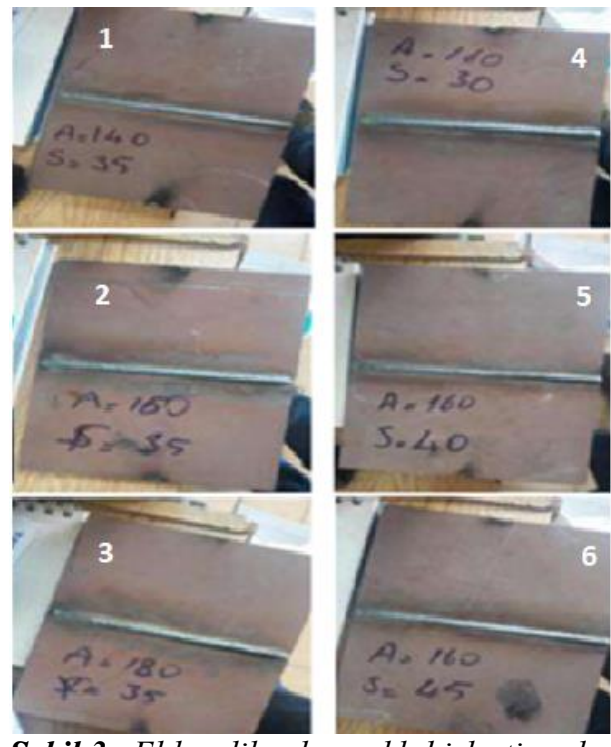

Şekil 3. Elde edilen kaynaklı birleştirmeler

\section{SONUCLAR VE TARTISMMA}

Elde etilen 6 farklı numuneden ana metal, geçiş bölgesi ve kaynak metalinden olmak üzere ortalama 35 ayrı noktadan $0,2 \mathrm{~mm}$ aralıklarla $200 \mathrm{~g}$ yükleme ile sertlik değerleri alınmıştır. Mikroyapısal inceleme sırasında da görülen, çelik üreticisi firma deneylerde kullanılan çelik çiftinin yapısında temperlenmiş martenzit yapısı ile metal karbür ve metal nitrür bileşimlerinin bulunduğunu belirtmiştirler $[1,15]$. Dolayısıyla yüksek sertlik değerlerinin ana malzemede görülmesi mümkündür. $\mathrm{Bu}$ nedenle ana malzemeden alınan sertlik değerlerinde yaklaşı $440 \mathrm{HV}_{0,2}$ olduğu ölçülmüştür. Ancak bu sertlik değeri kaynaklı birleştirmeler sonucunda malzemeye uygulanan yüksek 1s1 girdisi nedeniyle kaynak metalinde farklı sertlikler elde edilmiştir. Elde edilen sertlik değerleri incelendiğinde kaynak sırasında çelik çiftine uygulanan 1S1 girdisi sebebiyle ITAB bölgesinde temperlenmiş martenzit yapısının bozulmasından dolayı kaynaklı birleştirmelerin sertliklerinde düşüş olduğu gözlenmiştir.

Şekil 4'de 140 A akım şiddetinde ve $0,341 \mathrm{~kJ} / \mathrm{mm}$ 1sı girdisinde elde edilen 1. numunenin sertlik grafiği verilmiştir. Grafikte görüldüğü gibi ana malzemeden ITAB bölgesine geçildiğinde ana malzemenin sertliğinden daha düşük değerler elde edildiği gözlemlenmiştir. Kaynak bölgesinde en yüksek sertlik değerinin yaklaşık olarak 305 HV olduğu gözlemlenmektedir. 


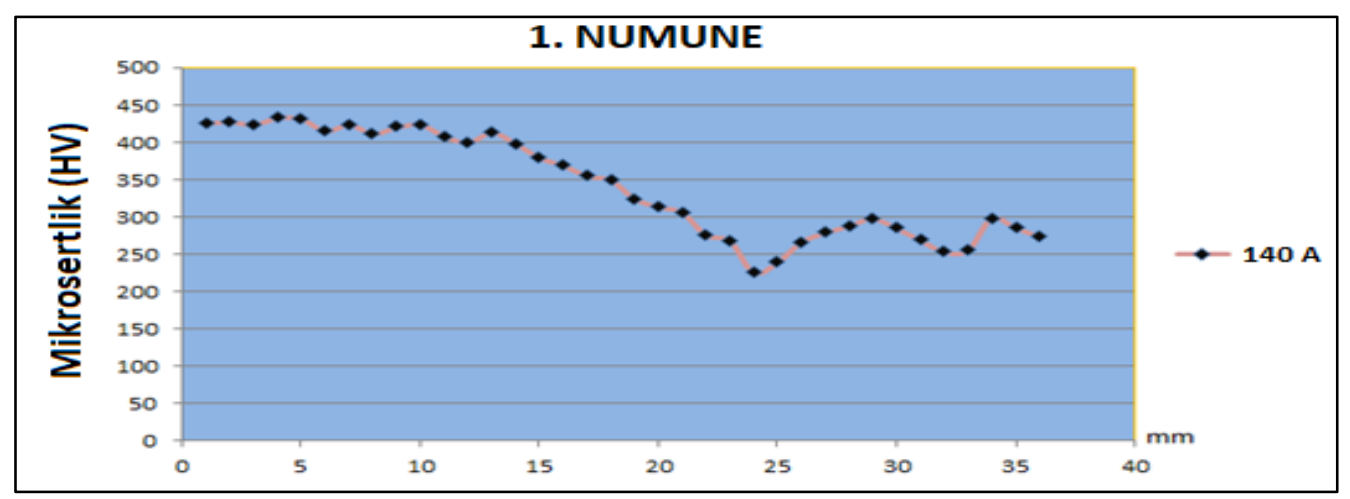

Şekil 4. 1.Numunenin (140A Akım şiddeti, 350 mm/dak kaynak hızı) sertlik grafiği

Şekil 5'de 160 A akım şiddeti ve $0,421 \mathrm{~kJ} / \mathrm{mm}$ 1sı girdisine sahip 2. numunenin sertlik grafiğgi verilmiştir. Kaynak akım şiddetinin artması ile 1S1 girdisinin arttı̆̆ ve ITAB'da setliğin daha fazla düştüğü gözlemlenmektedir. Kaynak bölgesinde en yüksek sertlik değerinin yaklaşık olarak $301 \mathrm{HV}$ olduğu gözlemlenmektedir.

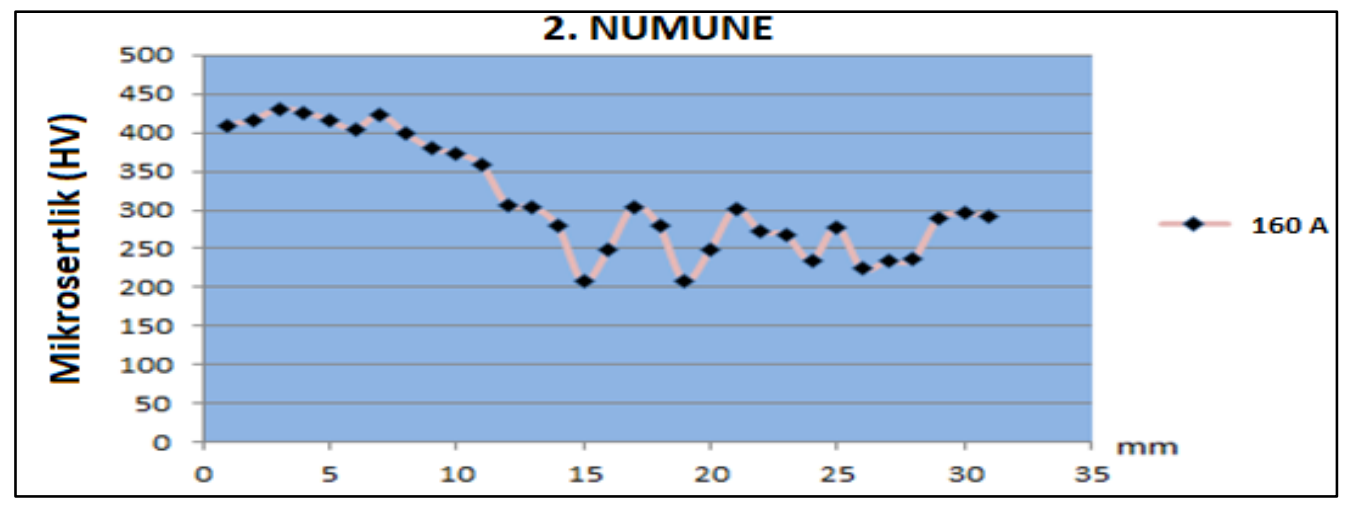

Şekil 5. 2.Numunenin (160A Akım şiddeti, $350 \mathrm{~mm} /$ dak kaynak hızı) sertlik grafiği

Şekil 6'de 180 A akım şiddeti ve $0,533 \mathrm{~kJ} / \mathrm{mm}$ 1s1 girdisine sahip 3. numunenin sertlik grafiği verilmiştir. Kaynak akım şiddetinin artması ile 1sı girdisinin arttığı ve ITAB'da setliğin daha fazla düştüğü gözlemlenmektedir. Kaynak bölgesinde en yüksek sertlik değerinin yaklaşık olarak $282 \mathrm{HV}$ olduğu gözlemlenmektedir.

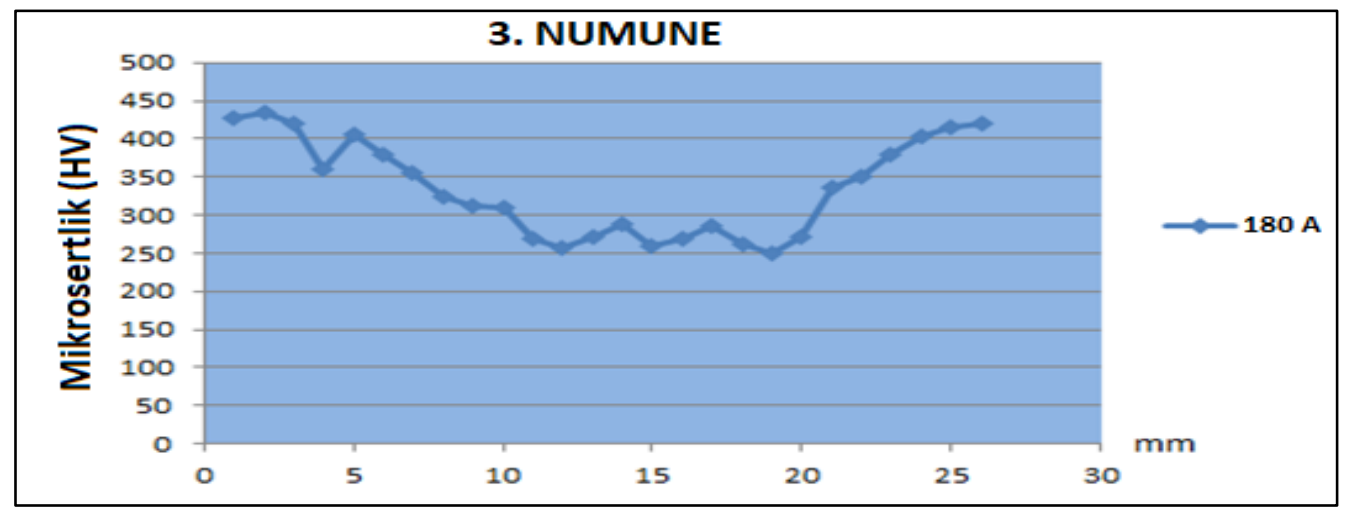

Şekil 6. 3.Numunenin (180A Akım şiddeti, 350mm/dak kaynak hızl) sertlik grafiği

Şekil 7'de üç farklı numunenin sertlik değerleri aynı grafik üzerinde verilmiş ve birbirleri ile karşılaştırılmıştır. Isı girdisinin artmasıyla birlikte soğuma süresinin de artmasından dolayı 3. numunede 
ITAB bölgesinde sertliğin en düşük seviyeye geldiği gözlenmiştir. ITAB bölgesinin bitiminde ana malzemeye yakın sertlik değerleri ölçülmüştür.

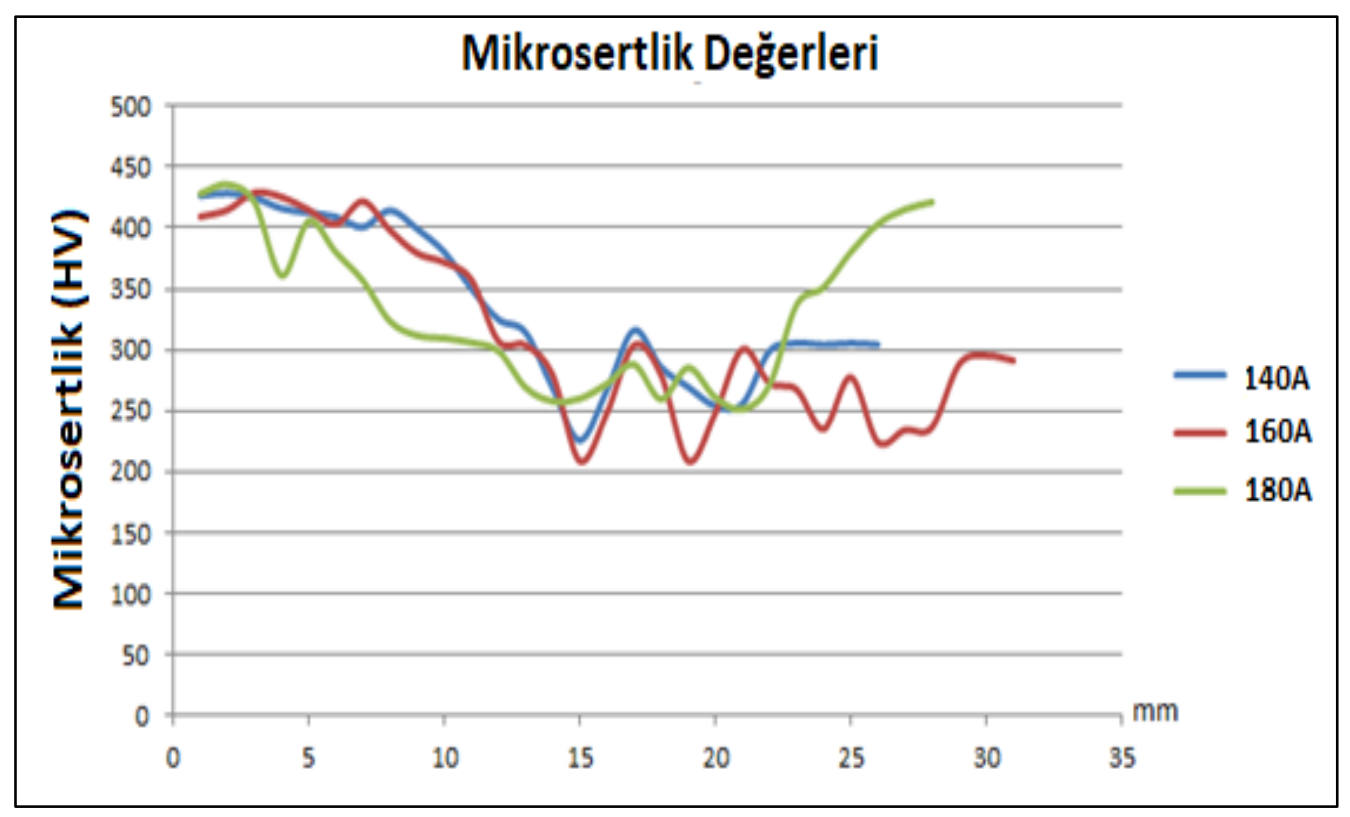

Şekil 7. 3 farklı numunenin (140 A,160 A ve 180 A Akım şiddeti, 350 mm/dak kaynak hızl) sertlik grafikleri

Farklı kaynak hizlarında ( $300 \mathrm{~mm} / \mathrm{dak}, 350 \mathrm{~mm} / \mathrm{dak}, 400 \mathrm{~mm} /$ dak ve $450 \mathrm{~mm} / \mathrm{dak}$ ) ve 160A kaynak akım şiddetinde elde edilmiş kaynaklı birleştirmelerden alınan sertlik değerleri Şekil 8, Şekil 9, Şekil 10, Şekil 11 ve Şekil 12’de verilmiştir.

Şekil 8'de 160 A akım şiddeti ve $0,491 \mathrm{~kJ} / \mathrm{mm}$ 1sı girdisine sahip 4. numunenin sertlik grafiği verilmiştir. Kaynak akım şiddetinin 160A' de sabit tutularak kaynak hızı 300 mm/dak seçilmiştir. Isı girdisinin arttığı ve ITAB' da setliğin daha fazla düştügü gözlemlenmektedir. Kaynak bölgesinde en yüksek sertlik değerinin yaklaşık olarak $281 \mathrm{HV}$ olduğu gözlemlenmektedir.

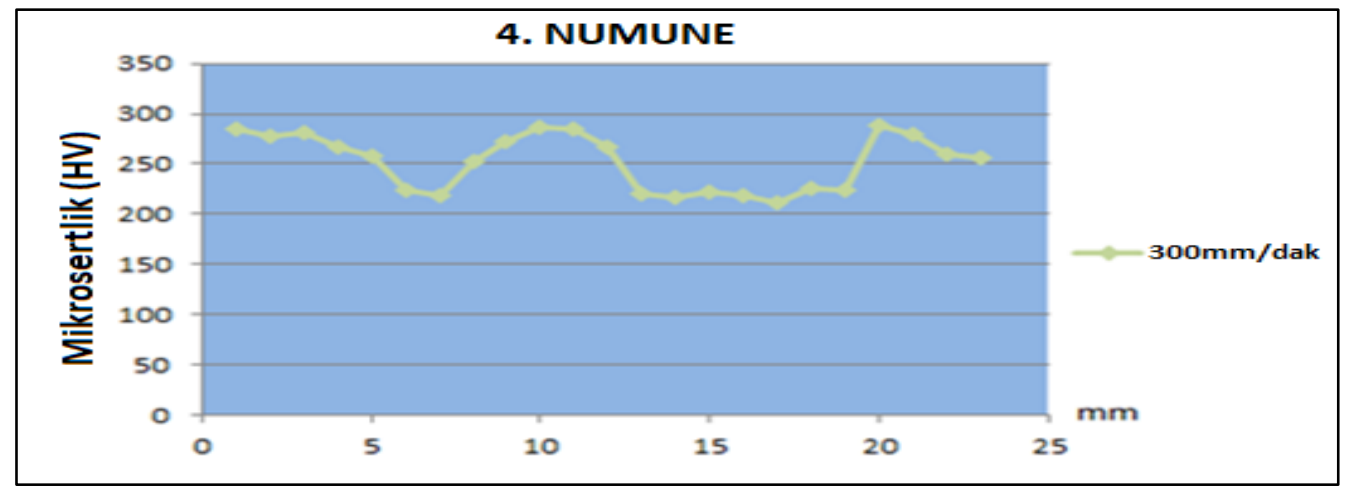

Şekil 8. 4. Numunenin (160 A ve 300 mm/dak kaynak hızl) sertlik grafikleri

Şekil 9'da 160 A akım şiddeti ve $0,421 \mathrm{~kJ} / \mathrm{mm}$ 1sı girdisine sahip 2. numunenin sertlik grafiğgi verilmiştir. Kaynak akım şiddetinin 160A'de sabit tutularak kaynak hız1 $350 \mathrm{~mm} /$ dak seçilmiştir. Isı girdisinin azalmasından dolayı ITAB'da setliğin daha fazla olduğu gözlemlenmektedir. Kaynak bölgesinde en yüksek sertlik değerinin yaklaşık olarak $301 \mathrm{HV}$ olduğu gözlemlenmektedir. 


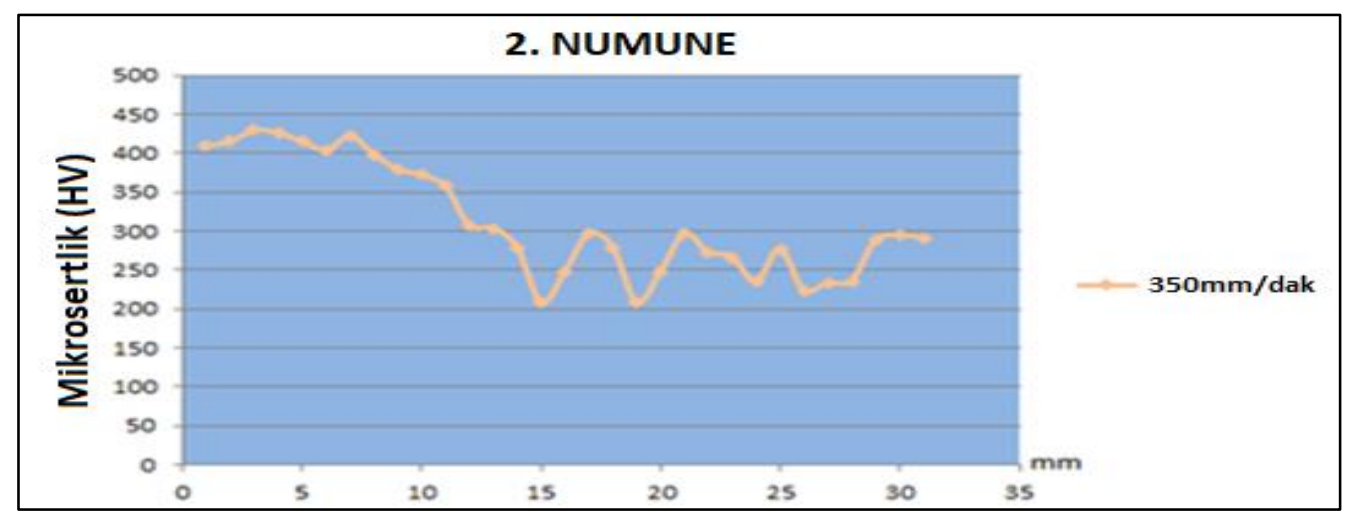

Şekil 9. 2. Numunenin (160 A ve $350 \mathrm{~mm} /$ dak kaynak hızl) sertlik grafikleri

Şekil 10'da 160 A akım şiddeti ve $0,368 \mathrm{~kJ} / \mathrm{mm}$ 1s1 girdisine sahip 5. numunenin sertlik grafiği verilmiştir. Kaynak akım şiddetinin 160A' de sabit tutularak kaynak hızı 400 mm/dak seçilmiştir. Isı girdisinin azalmasından dolayı soğuma süresi kısaldığından ITAB'da setliğin daha fazla olduğu gözlemlenmektedir. Kaynak bölgesinde en yüksek sertlik değerinin yaklaşık olarak $330 \mathrm{HV}$ olduğu gözlemlenmektedir.

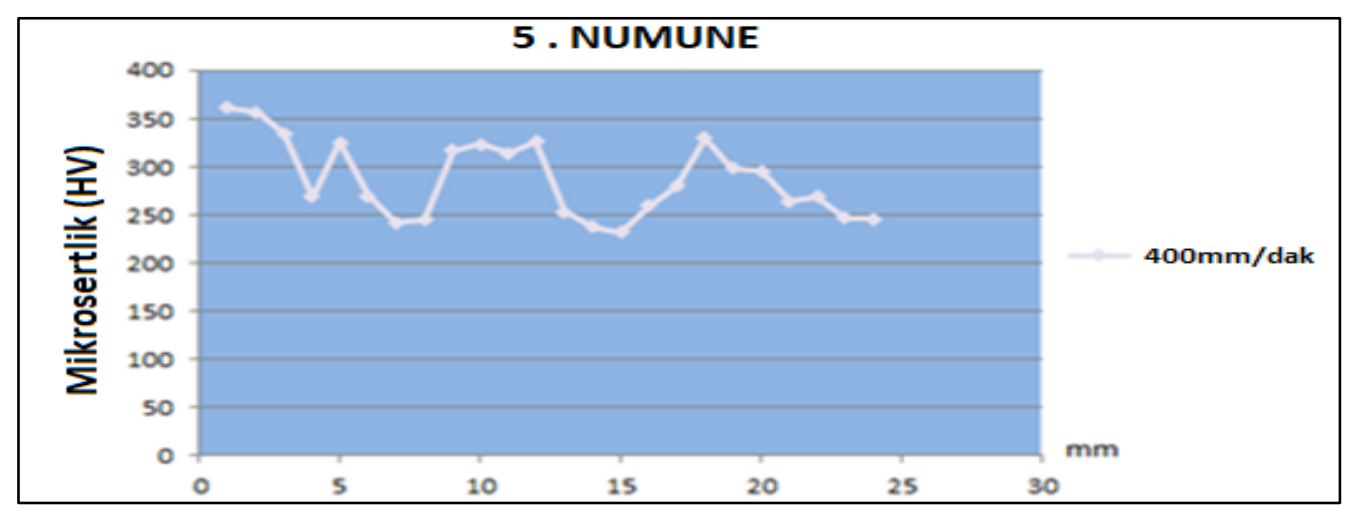

Şekil 10. 5. Numunenin (160 A ve 40 Omm/dak kaynak hızl) sertlik grafikleri

Şekil 11'de 160 A akım şiddeti ve $0,327 \mathrm{~kJ} / \mathrm{mm}$ 1s1 girdisine sahip 6. numunenin sertlik grafiği verilmiştir. Kaynak akım şiddetinin 160A' de sabit tutularak kaynak hızı $450 \mathrm{~mm} / \mathrm{min}$ seçilmiştir. Kaynak hızının artması ile ısı girdisinin azalmasından dolayı soğuma süresi kısaldığından ITAB'da setliğin en fazla olduğu parametre olarak gözlemlenmektedir. Kaynak bölgesinde en yüksek sertlik değerinin yaklaşık olarak $379 \mathrm{HV}$ olduğu gözlemlenmektedir.

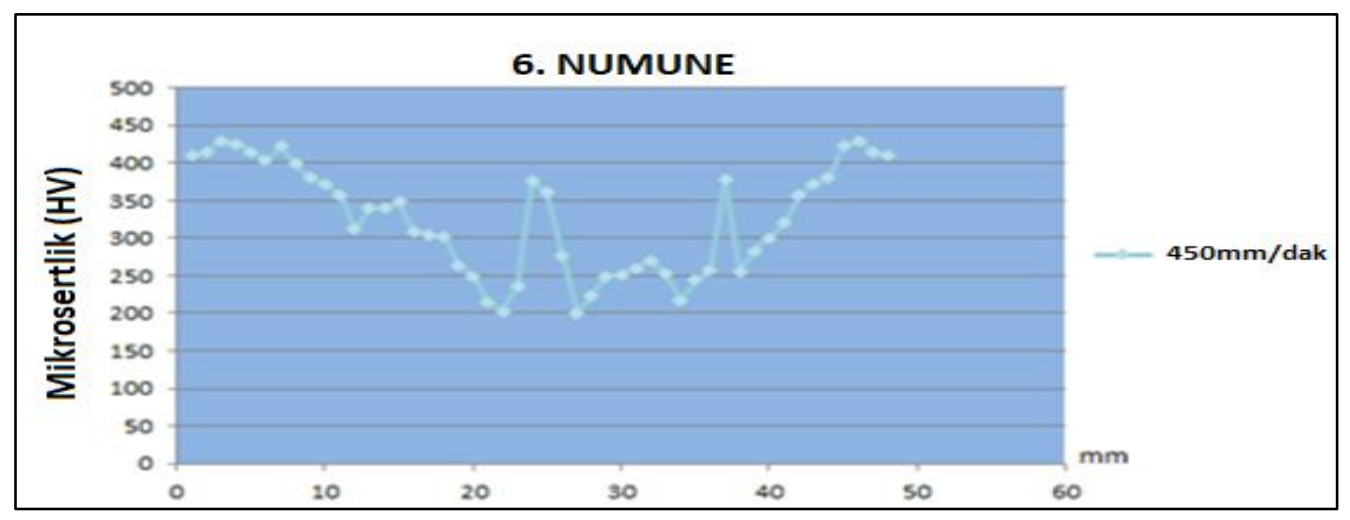

Şekil 11. 6. Numunenin (160 A ve $450 \mathrm{~mm} /$ dak kaynak hızl) sertlik grafikleri 
Şekil 12'de dört farklı kaynak hızına sahip ve 160A kaynak akım şiddeti kullanılarak elde edilen numunelerin sertlik değerleri aynı grafik üzerinde verilmiş ve birbirleri ile karşılaştırılmıştır. Isı girdisinin artmasıyla soğuma süresinin de artacağından dolayı 4. numunede ITAB bölgesinde sertliğin en düşük seviyeye geldiği gözlenmiştir. Aynı şekilde 1sı girdisinin en az olduğu ve soğuma süresini kısaldığ̀ 6 . numunede ITAB bölgesinde en yüksek sertliğe ulaşıldığ gözlemlenmiştir. ITAB bölgesinin bitiminde ana malzemeye yakın sertlik değerleri ölçülmüştür.

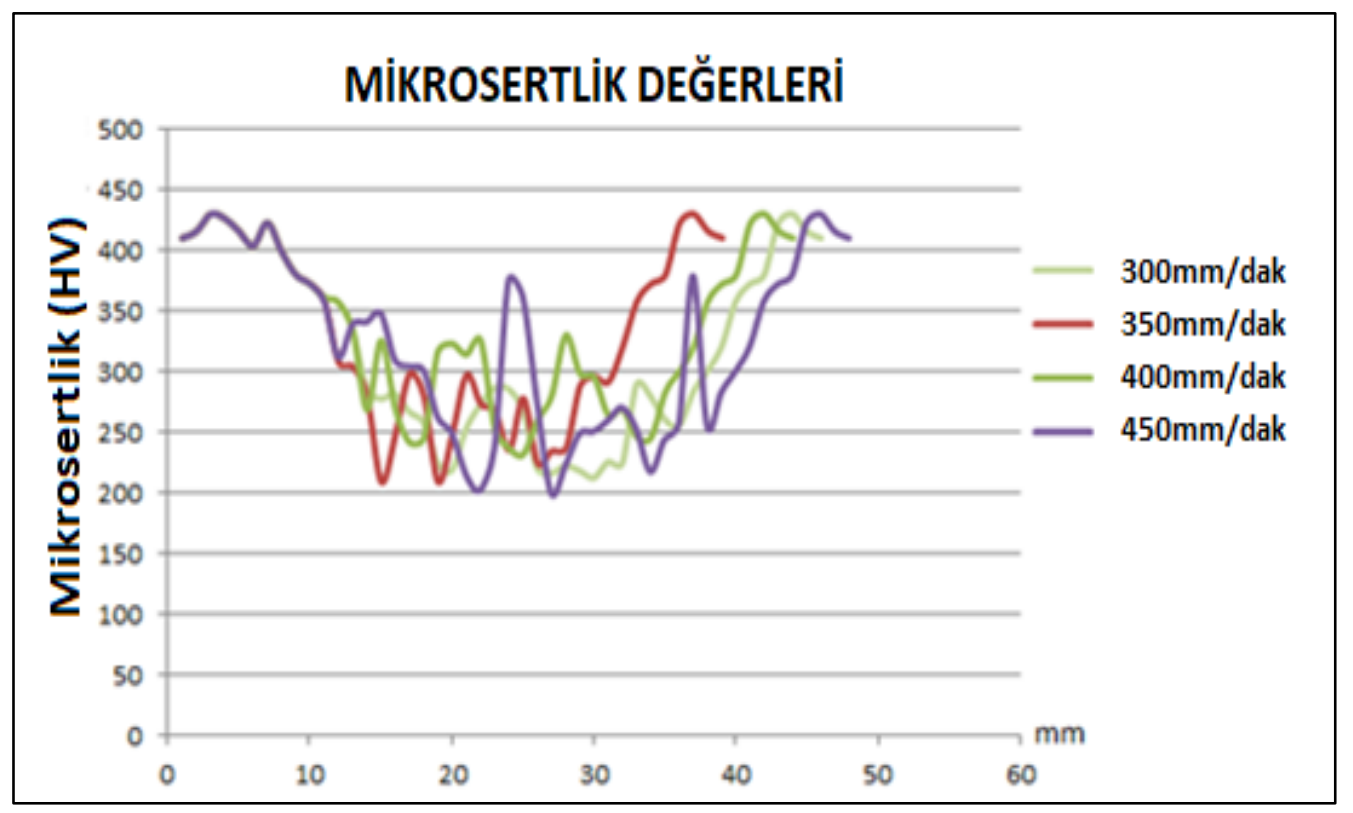

Şekil 12. 4 farkl numunenin (300 mm/dak,350 mm/dak, 400 mm/dak ve 450 mm/dak kaynak hizlarl, $160 \mathrm{~A}$ kaynak akım şiddetinde) sertlik grafikleri

\section{V.SONUC}

Yapılan kaynaklı birleştirmelerin hepsinde başarılı birleştirmeler elde edilmiştir. Numunelerin sertlik değerleri imalat çeliklerine göre farklılıklar göstermiştir. İmalat çeliklerinde ITAB bölgesinde kaba taneli yapıdan alınan sertlik değerleri ana malzeme sertliğinden fazla çıkarken, XAR çeliğinde sertlik değerleri ana malzemenin altında çıkmıştır. XAR çeliklerinin mikroyapısında bulunan temperlenmiş martenzit yapı kaynak sırasında bozulmuş bu yüzden de sertliklerde düşüş gözlenmiştir. Kaynak sırasında malzemelere uygulanan isı girdisinin fazlalığı sertlikteki düşüşü artırırken, düşük is girdilerinde soğumanın da hızlı olması ile birlikte sertlik değerleri özellikle kaynak metalinde artış olarak dikkat çekmektedir.

Bu bağlamda;

i. En yüksek $1 \mathrm{~s} 1$ girdisi $(0,533 \mathrm{~kJ} / \mathrm{mm})$ ile yapılan kaynaklı birleştirme numunesinden (3. Numune 180A) alınan farklı sertlik noktalarında ITAB bölgesinde en yüksek sertlik değeri $282 \mathrm{HV}$ olarak elde edilmiştir.

ii. En hızlı kaynak hızında (450 mm/dak) ve 160A kaynak akım şiddetinde yapılan birleştirmede 1S1 girdisinin düşük olması $(0,327 \mathrm{~kJ} / \mathrm{mm})$ sebebiyle ITAB bölgesinin kısa zamanda soğumasından dolayı ITAB bölgesindeki sertlik diğer numunelere göre daha yüksek $379 \mathrm{HV}$ olarak elde edilmiştir.

iii. Kaynak amperinin sabit tutulduğu (160A) 2, 4,5 ve 6. Numuneler kendi içlerinde incelendiğinde kaynak hızının düşük olduğu $300 \mathrm{~mm} /$ dak kaynak hızında en yüksek 1 sı girdisinde $(0,491 \mathrm{~kJ} / \mathrm{mm})$ ITAB bölgesinde en düşük sertlik değeri olarak 281 HV sertliği elde edilmiştir. 
iv. XAR çeliğinin kaynaklı birleştirmelerinde 1sı girdisinin az olduğu birleştirmelerde ITAB bölgesinde sertliğin az olduğu dolayısıyla da mekanik özelliklere olumlu yansıyacağı tespit edilmiştir.

v. Deneylerde yapılan kaynaklı birleştirmelerde en iyi kaynak parametresine sahip numunenin 4 . Numune (160A, 300mm/dak) olduğu kullanıcılara sunulmuştur.

\section{KAYNAKLAR}

[1] S. Frydman, G. Pękalski, "Structure and hardness changes in welded joints of Hardox steels," Archives of Civil and Mechanical Engineering, c. 8, s. 4, ss. 15-27, 2008.

[2] M. Oskwarek, "Structural features and susceptibility to cracking of welded joints of Hardox 400 and Hardox 500 steels," presented at the IV Scientific Conference of Students, Wroclaw University of Technology Publishing House, Wrocaw, Polland, 2006, ss. 115-120.

[3] H. Buglacki, M. Smajdor, "Mechanical properties of abrasion-resistant Hardox 400," Advances in Material Science, c. 4, s. 2, 64-71, 2003.

[4] P. Mithilesh, D. Varun, R. Ajay Gopi, K. Reddy, D. Ramkumar, N. Arivazhagan, S. Narayanan, "Investigations on dissimilar weldments of inconel 625 and AISI 304," Procedia Engineering, c. 75, ss. 66-70, 2014.

[5] Z. Li, G. Fontana, "Autogeneous laser welding of stainless steelto free-cutting steel for the manufacture of hydraulic valves," J. Mater. Process. Technol, c. 74, s. 1-3, ss. 174, 1998.

[6] M. Finsgar, L. Milosev, "Corrosion behavior of stainless steels in aqueous solutions of methanesulfonic acid," Corros. Sci., c. 52, s. 7, ss. 2430-2438, 2010.

[7] S.V. Konovalov, V.E. Kormyshev, V.E. Gromov, "Formation Wear Resistant Costings on Martensite Steel Hardox 450 by Welding Methods," IOP Conf. Ser.: Mater. Sci. Eng. 142, 012079, 2016, DOI: https://doi:10.1088/1757-899X/142/1/012079

[8] L. Konat, B. Bialobrzeska, P. Bialek, "Effect of Welding Process on Microstructural and Mechanical Characteristics of Hardox 600 Steel," c. 7, s. 9, ss. 1-18, DOI: https://doi:10.3390/met7090349

[9] Y. F. Ivanov, S.V. Konovalov, V. E. Kormyshev, V. E. Gromov, "Structure and Properties of Hardox 450 Steel with Arc Welded Coating," (020073), ss. 1-4, 1 DOI: https://doi.org/10.1063/1.5013754

[10] A. Uluköy, "Pulsed Metall Inert Gas (MIG) Welding And Its Effects On The Microstructure And Element Distribution Of An Aluminum Matrix Reinforced With Sic Composite Material," c. 48, s. 2, 163-176, DOI: https://doi.org/10.1002/mawe.201700568

[11] H. Ada, S. Aksöz, T. Fındık, C. Çetinkaya, B. Bostan, İ. Candan,"The Investigation of Effect of Welding Process on The Microstructure and Mechanical Properties of API 5L X65 Steel Welded with Gas Metal Arc Welding Method," Çukurova University Journal of the Faculty of Engineering and Architecture, 31(ÖS 1), ss.1-9, 2016. 
[12] M. Ekici, U. Ozsaraç, "Investigation of Mechanical Properties of Microalloyed Steels Joined by GMAW and Electrical Arc Welding," ACTA PHYSICA POLONICA A, c. 123, s. 2, ss. 289-290, DOI: https://doi.org/10.12693/APhysPolA.123.289

[13] M. Ekici, U. Ozsarac, "Influence of Martensite Volume Fraction on Ductile to Brittle Transition of Triple Phase Ferrite-Perlite-Martensite Steels Joined by GMAW and Electrical Arc Welding," ACTA PHYSICA POLONICA A, c. $125, \quad$ s. 2, $\quad$ ss. 529-531, $\quad$ DOI: https://doi.org/10.12693/APhysPolA.125.529

[14] P.J. Modenesi, R.C. Avelar, "The Influence Of Small Variations of Wire Characteristics on Gas Metal Arc Welding Process Stability," Journal of Materials Processing Technology, c. 86, s. 1-3, ss. 226-232, DOI: https://doi.org/10.1016/S0924-0136(98)00315-X

[15] M.G. Çınar, V. Onar, H. Efe, " Microstructure Analysis of XAR Steel Plate Welded by MAG Weldıng Method Using Different Welding Currents," International Journal on Mathematic, Engineering and Natural Science”, c. 3, s.7, ss. 22-29, 2019.

[16] H. Efe, V. Onar, M.G. Çınar, " The Effect of Welding Currents on Microstructures in Welding of S690QL Series Steel in Used Heavy Duty Machines," International Journal on Mathematic,Engineering and Natural Science”, c. 3, s. 8, ss. 123-130, 2019.

[17] A.K. Gür, T. Yıldız, U. Çalıgüllü, Ç. Özay, "AISI 304/HARDOX 400 Çelik Çiftlerinin PTA Kaynak Yöntemiyle Birleştirilmesinde Kaynak Gücünün Etkisi,” IMSMATEC18, İzmir, Türkiye, 2018, ss. $250-256$.

[18] G. G. Corea, R. F. Silva,, L. C. Silva, "Weldabilitiy of Abrasion-Resistant Steels of 450 HB Hardness," Soldag. Insp., c.16, s. 4, ss. 360-368, 2011.

[19] C. T. Tevfik, "Weldable of HARDOX 450 Steel with Submerged Welding Method," ICETAS, Afyon, Türkiye, 2016, ss. 590-593.

[20] L. Konat, B. Bialobreska, P. Bialek, "Effect of Welding Process on Microstructural an Mechanical Charestersitics of Hardox 600 Steel,” Metals, c. 7, s. 9, ss. 349-366, 2017.

[21] M. Bramowizc, S. Kulesza, P. Lewalski, P. Szatkowski, "Structural Studies of Welds in WearResistant Steels,” ACTA PHYSICA POLONICA A, C.130, S.4, ss. 963-965, 2016. 